(2) Open Access Full Text Article

\title{
Impact of clerkship attachments on students' attitude toward pharmaceutical care in Ethiopia
}

This article was published in the following Dove Press journal:

Advances in Medical Education and Practice

20 May 2015

Number of times this article has been viewed

Bayew Tsega'

Akshaya Srikanth

Bhagavathula'

Barun Ranjan Sarkar'

Tadesse Melaku'

Zewdneh Shewamene ${ }^{2}$

'Department of Clinical Pharmacy, ${ }^{2}$ Department of Pharmacology, School of Pharmacy, University of Gondar-

College of Medicine and Health

Sciences, Gondar, Ethiopia
Correspondence: Bayew Tsega

Department of Clinical Pharmacy, School of Pharmacy, University of Gondar-

College of Medicine and Health Sciences, PO Box 196, Gondar, Ethiopia

$\mathrm{Tel}+25$ I 937644920

Fax $+25|588 I| 9090$

Email bayew.tsega@uog.edu.et
Objective: The study objective is to investigate the impact of mandatory clinical clerkship courses on 5th-year pharmacy students' attitudes and perceived barriers toward providing pharmaceutical care (PC).

Methods: A cross-sectional survey was conducted among 5th-year pharmacy students undertaking mandatory clinical clerkship in the University of Gondar, Ethiopia. A pharmaceutical care attitudes survey (PCAS) questionnaire was used to assess the attitude (14 items), commonly identified drug-related problem/s (1 item) during clerkships, and perceived barriers (12 items) toward the provision of PC. Statistical analysis was conducted on the retrieved data.

Results: Out of the total of 69 clerkship students, 65 participated and completed the survey (94.2\% response rate). Overall, $74.45 \%$ of participants opinioned a positive attitude toward PC provision. Almost all respondents agreed that the primary responsibility of pharmacists in the healthcare setting was to prevent and solve medication-related problems $(98.5 \%)$, practice of PC was valuable (89.3\%), and the PC movement will improve patient health (95.4\%), respectively. Unnecessary drug therapy (43\%), drug-drug interactions (33\%), and non-adherence to medications $(33 \%)$ were the most common drug-related problems identified in wards. Highly perceived barriers for PC provision included lack of a workplace for counseling in the pharmacy (75.4\%), a poor image of pharmacist's role in wards $(67.7 \%)$, and inadequate technology in the pharmacy $(64.6 \%)$. Lack of access to a patient's medical record in the pharmacy had significant association $(P<0.05)$ with PC practice, performance of PC during clerkship, provision of PC as clinical pharmacists, and Ethiopian pharmacists benefiting by PC.

Conclusion: Ethiopian clinical pharmacy students have a good attitude toward PC. Efforts should be targeted toward reducing these drug therapy issues, and aiding the integration of PC provision with pharmacy practice.

Keywords: students, Ethiopia, clinical pharmacy program, clerkship, pharmaceutical care

\section{Introduction}

The roles of a pharmacist in clinical pharmacy practice have widened from providing the traditional compounding and dispensing services to patient-oriented care such as optimization of medication therapy and promoting health, wellness, and disease prevention by pharmaceutical care (PC). ${ }^{1} \mathrm{PC}$ is an evidence-based practice that ensures a rational use of drug therapy for diseases and prevention of drug-related problems. ${ }^{2}$ Several studies have shown that PC services can influence optimal drug therapy, save lives, and enhance a patient's quality of life. ${ }^{3,4}$ Clinical pharmacy practice is well recognized and practiced in developed countries like the United States, Australia, Brazil, and many European countries. ${ }^{5}$ Developing countries like India, Pakistan, and Middle East have changed their curriculum to emphasize the need to 
provide more clinical knowledge in addition to industrial knowledge to pharmacists. ${ }^{6}$ In Ethiopia, a new clinical pharmacy program was established in 2008 with an objective of training patient-centered pharmacy practitioners by extending the 4-year undergraduate pharmacy program to a 5-year clinical pharmacy program with clerkship. ${ }^{7}$ In March 2009, the School of Pharmacy of Jimma University launched the nation's first graduate program for training both the clinical pharmacy practitioners as well as the faculty members for the new undergraduate clinical pharmacy program as part of the National Harmonized Modular Curriculum program for the Bachelor of Pharmacy degree. ${ }^{8,9}$ Successively, the University of Gondar-School of Pharmacy (UoG-SP) adopted the 5-year clinical pharmacy program (10 semesters, 300 credit hours), including 4 years of academic study with 1-year clinical clerkship. These clerkship courses are conducted in various departments for 43 credit hours/week, and include ambulatory care ( 7 credit hours), pediatrics ( 7 credit hours), psychiatry ( 3 credit hours), drug information service ( 3 credit hours), hospital pharmacy ( 5 credit hours), internal medicine ( 7 credit hours), surgery ( 3 credit hours), community pharmacy (5 credit hours), and gynecology and obstetrics and family planning ( 3 credit hours). The clinical clerkship only starts after the 4 th year students take elective courses in areas such as diabetes, HIV/AIDS, and pharmaceutical manufacturing with ongoing continuous assessment combined with 6 months of academic research. The main focus of these clerkships is to provide knowledge to student pharmacists about PC and ensure the optimal use of medicines by the patients, identify and resolve drug-related problems through patient information retrieval and assessment, develop patient-specific pharmacotherapy care plans, provide patient education and training, and collaborate with other healthcare teams in various wards. Clinical clerkship involves active experiential rotations of pharmacy students in various clinical wards and provides opportunity to assist PC services in various pharmacy practice sites under the supervision of expert preceptors, guiding them to build the patient-pharmacist interaction and ensure positive working experience with interdisciplinary healthcare teams in the clinical decision-making processes. To date, there have been no studies evaluating the attitude of clinical pharmacy students undertaking mandatory clinical clerkship courses in Ethiopia. Hence, this study determined the impact of mandatory clinical clerkship courses on the 5th-year pharmacy students' attitudes and perceived barriers toward providing PC.

\section{Methods}

This cross-sectional survey was conducted at UoG-SP. All the 5th-year clinical pharmacy students who underwent 1-year mandatory clinical clerkship courses in UoG-SP were approached to participate in the study. Ethical approval was obtained from the Institutional review board of UoG-SP.

\section{Assessment tool}

A self-administered survey was used in the study. The investigators designed the study survey based on the standard pharmaceutical care attitudes survey (PCAS). PCAS is a validated instrument that measures students' attitude toward PC. It was developed in the United States and has already been used in previous studies conducted in Nigeria, the Kingdom of Saudi Arabia, Qatar, Pakistan, and the United States. ${ }^{10-16}$ The draft survey was distributed to ten faculty members at UoG-SP to assess its readability and content validity, and was further pretested among four randomly selected pharmacy students at UoG-SP for clarity, relevance, and acceptability. Refinements were made as required to facilitate better comprehension and organize questions before distributing the final survey among the study population. The 5th-year students who finished mandatory clinical clerkship and completed the course were requested to complete the questionnaire. No financial incentives were provided to the study participants who were encouraged to participate voluntarily.

\section{Content of the study tool}

The final structured survey questionnaire was mainly composed of four sections with a total of 32 items, comprising of pharmacy students' sociodemographic characteristics (5 items), pharmacy students' attitudes toward PC based on the PCAS survey (14 items), commonly identified drug-related problem/s during clerkships (1 item), and pharmacy students' perceived barriers toward provision of PC (12 items).

Sociodemographic characteristics included sex, age, religion, marital status, and social habits. To assess the students' attitudes toward PC, a 14-item questionnaire (PCAS) with a 5-point Likert scale ranging from "strongly agree $=5$ " to "strongly disagree $=1$ " was utilized. The PCAS score of each statement (range 1-15) were summed. Scores greater than nine were interpreted to be a positive attitude, eight as neutral, and 1-7 as a negative attitude. ${ }^{17}$ The Likert scale measured the extent of student agreement with statements regarding PC. These statements were adopted from previous studies using the PCAS survey. ${ }^{10-16}$ Eleven were positively worded, two were negatively worded, and one was related to 
motivation. The two negative items (6 and 13) were reverse scored during the analysis so that higher scores reflected more positive attitudes toward PC.

One question was related to the practicality of commonly identified drug-related problems observed in wards and encouraged participants to select at least one to three options out of ten options. Ten items were included to identify the perceived barriers that would prevent clerkship students from providing PC to patients, by means of a 3-point Likert scale (high, medium, and low). The Likert scale indicated the extent to which each of the listed barriers would impede the provision of PC by the students in the future. The barriers included: inadequate drug information resources, lack of access to patient medical records in the pharmacy, lack of therapeutics knowledge, lack of understanding of $\mathrm{PC}$, inadequate training in PC, time constraints, and other barriers.

Data from the completed survey was first entered in Microsoft Excel 2007, and then analyzed using Statistical Package for Social Science Version 22, Chicago, IL, USA. Sociodemographic characteristics were summarized as descriptive statistics and inferential analysis. The mean, standard deviation, median, interquartile range, and percentage were computed for all PCAS statements. Correlation between barrier statements was determined using multiple logistic regression. In all statistical analyses, a $P$-value of $<0.05$ was considered to be statistically significant.

\section{Results}

A total of 69 clerkship students were approached out of which 65 agreed to participate and completed the survey. The overall response rate was $94.2 \%$.

\section{Students' sociodemographic characteristics}

In this study, the majority of respondents were males (93.8\%), under 20-25 years of age (89.2\%), were Christians (76.9\%), single (93.8\%), and did not have any social habits (90.8\%) such as smoking, alcohol consumption, or eating khat.

\section{Students' attitude toward PC}

The mean \pm standard deviation of the PCAS scores representing pharmacy students' attitude toward providing PC are tabulated in Table 1. Overall, $74.45 \%$ of clerkship students had very positive attitude toward PC provision. Almost all respondents agreed that the primary responsibility of pharmacists in the healthcare setting was to prevent and solve medication-related problems (98.5\%), practice of PC was valuable (89.3\%), and the PC movement will improve patient health $(95.4 \%)$, respectively. Further, $73.8 \%$ of the participants agreed that the PC movement will benefit the pharmacists in Ethiopia. However, $80 \%$ of respondents believed that the provision of PC took too much time and effort. Out of the 14 PCAS statements, items 6 and 13 were reversely scored, and only $3.1 \%$ and $10.8 \%$ clerkship students strongly disagreed with these statements respectively.

\section{Most commonly identified drug-related problems}

The most commonly identifiable drug-related problems observed by the students, during their clerkship in the ward included unnecessary drug therapy (43\%), drug-drug interactions (33\%), non-adherence to medications (33\%), additional need for drug therapy (15\%), and non-compliance to medications $(17 \%)$, respectively (Figure 1).

\section{Students' perceived barriers for PC provision}

Barriers perceived highly by students as that prevented them from providing PC included lack of workplace for counseling in the pharmacy $(75.4 \%)$, a poor image of pharmacist's role in wards $(67.7 \%)$, inadequate technology in the pharmacy $(64.6 \%)$, inadequate drug information resources in the pharmacy $(53.8 \%)$, lack of access to patient medical records in the pharmacy $(50.8 \%)$, and inadequate training in PC (50.8\%) (Table 2).

The $P$-values within each barrier statements are summarized in Table 3. Significant positive correlation was noted between each barrier. Lack of access to patient medical records in the pharmacy was found to have a significant association with lack of therapeutic knowledge (0.000), lack of understanding PC (0.002), inadequate technology (0.000), and a poor image of pharmacy (0.0001). In addition, significant association was found between lack of therapeutic knowledge and statements lack of access to medical records (0.000), lack of understanding PC (0.001), inadequate technology (0.000), poor pharmacist's role in wards $(0.000)$, and inability to deal with a different sex (0.004) (Table 3).

\section{Discussion}

This study is the first to investigate several aspects related to the attitudes and barriers experienced by Ethiopian pharmacy students with respect to PC provision during clerkships. It showed that the clerkship courses taught to the final year pharmacy students in Ethiopia made their attitude highly positive 
Table I Pharmacy students attitudes toward PC per PCAS items $(\mathrm{N}=65)$

\begin{tabular}{|c|c|c|c|c|c|c|c|}
\hline \multirow[t]{3}{*}{ Statements } & \multicolumn{5}{|c|}{ Frequency (percentage) } & \multirow[t]{3}{*}{ Mean \pm SD $(95 \% \mathrm{Cl})$} & \multirow{3}{*}{$\begin{array}{l}\text { Mediar } \\
\text { IQR }\end{array}$} \\
\hline & \multicolumn{5}{|c|}{$\begin{array}{l}\text { Please indicate your extent of agreement } \\
\text { with the following statements regarding } \\
\text { your attitude toward PC }\end{array}$} & & \\
\hline & $\begin{array}{l}\text { Strongly } \\
\text { agree }\end{array}$ & Agree & Neutral & Disagree & $\begin{array}{l}\text { Strongly } \\
\text { disagree }\end{array}$ & & \\
\hline I. All pharmacists should perform PC. & $39(60)$ & $19(29.2)$ & $\mathrm{I}(\mathrm{I} .5)$ & $5(7.7)$ & I (I.5) & $1.62 \pm 0.963(1.38-1.81)$ & $I(I-5)$ \\
\hline $\begin{array}{l}\text { 2. Primary responsibility of pharmacists in } \\
\text { healthcare setting should be to prevent } \\
\text { and solve medication-related problems. }\end{array}$ & $49(75.4)$ & $15(23.1)$ & $0(0.0)$ & $\mathrm{I}(\mathrm{I} .5)$ & $0(0.0)$ & $1.28 \pm 0.542(1.14-1.41)$ & $I(I-4)$ \\
\hline $\begin{array}{l}\text { 3. Pharmacists' primary responsibility } \\
\text { should be to practice PC. }\end{array}$ & $49(64.6)$ & $19(29.2)$ & $\mathrm{I}(\mathrm{I} .5)$ & $3(4.6)$ & $0(0.0)$ & $1.46 \pm 0.752(1.28-1.66)$ & $I(I-4)$ \\
\hline $\begin{array}{l}\text { 4. Pharmacy students can perform } \\
\text { PC during their clerkship. }\end{array}$ & $27(4 \mid .5)$ & $25(38.5)$ & $6(9.2)$ & $6(9.2)$ & $\mathrm{I}(\mathrm{l} .5)$ & $1.91 \pm 1.011(1.66-2.27)$ & $2(I-5)$ \\
\hline 5. I think the practice of PC is valuable. & $43(66.2)$ & $15(23.1)$ & $2(3.1)$ & $4(6.2)$ & $\mathrm{I}(\mathrm{I} .5)$ & $\mathrm{I} .54 \pm 0.937(\mathrm{I} .33-\mathrm{I} .77)$ & $I(I-5)$ \\
\hline 6. Providing PC takes too much time and effort. & $36(55.4)$ & $16(24.6)$ & $5(7.7)$ & $6(9.2)$ & $2(3.1)$ & $\mathrm{I} .80 \pm \mathrm{I} .12 \mathrm{I}(\mathrm{I} .55-2 . \mathrm{II})$ & $I(I-5)$ \\
\hline $\begin{array}{l}\text { 7. I would like to perform PC as a clinical } \\
\text { pharmacist. }\end{array}$ & $33(50.8)$ & $16(24.6)$ & $5(7.7)$ & $9(13.8)$ & $2(3.1)$ & $1.94 \pm 1.197(1.69-2.25)$ & $I(I-5)$ \\
\hline $\begin{array}{l}\text { 8. Providing PC is professionally rewarding } \\
\text { during my clerkship. }\end{array}$ & $16(24.6)$ & $27(4 \mid .5)$ & $14(2 \mid .5)$ & $5(7.7)$ & $2(3.1)$ & $2.22 \pm 1.015(1.98-2.48)$ & $2(I-5)$ \\
\hline $\begin{array}{l}\text { 9. I feel that the PC is the right direction } \\
\text { for my career. }\end{array}$ & $25(38.5)$ & $20(30.8)$ & $6(9.2)$ & $13(20)$ & $\mathrm{I}(\mathrm{I} .5)$ & $2.15 \pm 1.189(1.88-2.45)$ & $2(I-5)$ \\
\hline $\begin{array}{l}\text { 10. I feel that PC movement would benefit } \\
\text { pharmacists in Ethiopia. }\end{array}$ & $27(4 \mid .5)$ & $21(32.3)$ & $10(15.4)$ & $5(7.7)$ & $2(3.1)$ & $1.98 \pm 1.082(1.77-2.28)$ & $2(I-5)$ \\
\hline $\begin{array}{l}\text { II. I feel that PC movement will improve } \\
\text { patient health. }\end{array}$ & $46(70.8)$ & $16(24.6)$ & $3(4.6)$ & $0(0.0)$ & $0(0.0)$ & $1.34 \pm 0.567(1.20-1.47)$ & $I(I-3)$ \\
\hline $\begin{array}{l}\text { I2. I feel that practicing PC will benefit } \\
\text { my professional pharmacy career } \\
\text { as a clinical pharmacist. }\end{array}$ & $32(49.2)$ & $26(40)$ & $2(3.1)$ & $3(4.6)$ & $2(3.1)$ & $1.72 \pm 0.960(1.53-1.98)$ & $2(I-5)$ \\
\hline $\begin{array}{l}\text { 13. Providing PC is not worth the additional } \\
\text { workload that it places on the pharmacist. }\end{array}$ & $7(10.8)$ & $17(26.2)$ & $15(23.1)$ & $19(29.2)$ & $7(10.8)$ & $3.03 \pm 1.119(2.8 I-3.39)$ & $3(1-5)$ \\
\hline 14. I feel proud to be a clinical pharmacist. & $33(50.8)$ & $17(26.2)$ & $8(12.3)$ & $3(4.6)$ & $4(6.2)$ & $1.89 \pm 1.174(1.64-2.19)$ & $I(I-5)$ \\
\hline
\end{tabular}

Abbreviations: PC, pharmaceutical care; PCAS, pharmaceutical care attitudes survey; IQR, interquartile range.

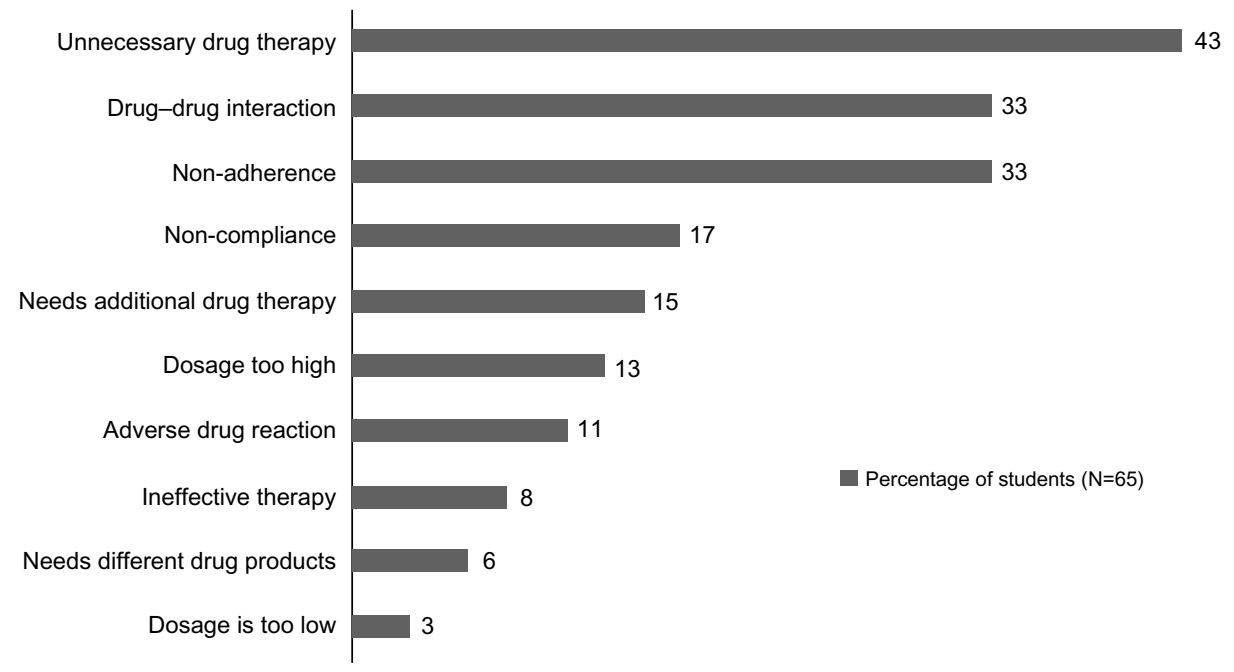

Figure I Most identified drug-related problems by the students $(\mathrm{N}=65)$.

toward providing PC. Similar studies conducted in Pakistan, Nigeria, the United States, and Saudi Arabia showed positive attitude toward the provision of pharmacy care services among pharmacy students upon completion of clerkship. . $11,12,16,18^{2}$
PC provision in the medical wards is a multifaceted process that involves identifying, preventing, and resolving drug therapy problems. Some of the most common types of drug therapy problems observed by the pharmacy students 
during the course of clerkship were unnecessary drug therapy (43\%), followed by drug-drug interactions (33\%) and nonadherence (33\%).

The most common barrier highlighted by the clerkship students in our study as that impeding the provision of PC was the lack of space for counseling in the pharmacy (75.4\%). The percentage of students stating this barrier was much

Table 2 Students' perceived barriers for PC provision ( $\mathrm{N}=65)$

\begin{tabular}{|c|c|c|c|}
\hline \multirow[t]{3}{*}{ Barrier } & \multicolumn{3}{|c|}{ Frequency (percentage) } \\
\hline & \multicolumn{3}{|c|}{$\begin{array}{l}\text { To what extent would each of } \\
\text { the following barriers prevent } \\
\text { you from providing PC when } \\
\text { you become a pharmacist in } \\
\text { the future? }\end{array}$} \\
\hline & $\begin{array}{l}\text { High } \\
\text { extent }\end{array}$ & $\begin{array}{l}\text { Moderate } \\
\text { extent }\end{array}$ & $\begin{array}{l}\text { Low } \\
\text { extent }\end{array}$ \\
\hline $\begin{array}{l}\text { Inadequate drug information } \\
\text { resources in the pharmacy }\end{array}$ & $35(53.8)$ & $25(38.5)$ & $5(7.7)$ \\
\hline $\begin{array}{l}\text { Lack of access to patient medical } \\
\text { records in the pharmacy }\end{array}$ & $33(50.8)$ & $29(44.6)$ & $3(4.6)$ \\
\hline Lack of therapeutics knowledge & $17(26.2)$ & $32(49.2)$ & $16(24.6)$ \\
\hline Lack of understanding of PC & $16(24.6)$ & $22(33.8)$ & $27(4 I .5)$ \\
\hline Inadequate training in $\mathrm{PC}$ & $33(50.8)$ & $24(36.9)$ & $8(12.3)$ \\
\hline $\begin{array}{l}\text { Lack of workplace for counseling } \\
\text { in the pharmacy }\end{array}$ & $49(75.4)$ & $14(2 \mid .5)$ & $2(3.1)$ \\
\hline $\begin{array}{l}\text { Inadequate technology in the } \\
\text { pharmacy }\end{array}$ & $42(64.6)$ & $21(32.3)$ & $2(3.1)$ \\
\hline Lack of self confidence & $12(18.5)$ & $27(4 I .5)$ & $26(40)$ \\
\hline Time constraints (lack of time) & $18(27.7)$ & $28(43.1)$ & $19(29.2)$ \\
\hline $\begin{array}{l}\text { Poor image of pharmacist's role } \\
\text { in wards }\end{array}$ & $44(67.7)$ & $17(26.2)$ & $4(6.2)$ \\
\hline Inability to deal with a different sex & $10(15.4)$ & $22(33.8)$ & $33(50.8)$ \\
\hline Religious constraint & $7(10.8)$ & $12(18.5)$ & $46(70.8)$ \\
\hline
\end{tabular}

Abbreviation: PC, pharmaceutical care. higher than that observed in Qatar study (44\%). ${ }^{14}$ Some of the reasons for this perceived barrier might be lack of infrastructure, smaller facilities, and patient overload. Another perceived barrier preventing the provision of PC in our study was the poor image of the pharmacist in Ethiopian hospitals. This is unfortunate, since several studies have demonstrated the effectiveness of pharmacist-delivered PC services to improve clinical, humanistic, and economic conditions. ${ }^{17,19}$ The development of PC necessitates positive attitude among the public. The students also identified inadequate technology in pharmacies as an impediment in delivering PC. This finding is consistent with the previous studies conducted in community pharmacies in People's Republic of China and Northern Ireland. ${ }^{20,21}$ The study confirmed that Ethiopian pharmacies have limited access to electronic resources and have limited resources in general. The implementation of PC in Ethiopia will require availability of technological support in pharmacies along with the needed resources that facilitate patient care, such as electronic medical records, electronic decision support, and computerized patient-order entry.

The data from our study suggests that participants who had more practical experience had more positive attitude toward PC. It is also possible that since this was the first batch of pharmacy students undertaking mandatory clinical clerkships in Ethiopia, the general attitude toward providing PC was positive. More research is needed to evaluate how the knowledge acquired during clerkship training translates into an actual practice in Ethiopia once the pharmacy students graduate. As the clinical pharmacy is in its nascent stages in Ethiopia, PC is not yet offered at pharmacy practice sites. If the pharmacy students are exposed to high-level

Table 3 Factors associated with students' response for each barrier statements

\begin{tabular}{|c|c|c|c|c|c|c|c|c|c|c|c|c|}
\hline Number & Barrier statements & I & 2 & 3 & 4 & 5 & 6 & 7 & 8 & 9 & 10 & II \\
\hline I & $\begin{array}{l}\text { Inadequate drug information } \\
\text { resources in the pharmacy }\end{array}$ & 1 & 0.51 & 0.090 & 0.230 & 0.450 & 0.288 & 0.031 & 0.169 & 0.426 & 0.347 & 0.268 \\
\hline 2 & $\begin{array}{l}\text { Lack of access to the patient } \\
\text { medical record in the pharmacy }\end{array}$ & 0.51 & I & 0.000 & 0.002 & 0.463 & 0.206 & 0.000 & 0.324 & 0.248 & 0.001 & 0.180 \\
\hline 3 & Lack of therapeutic knowledge & 0.090 & 0.000 & I & 0.001 & 0.279 & 0.415 & 0.000 & 0.013 & 0.422 & 0.000 & 0.004 \\
\hline 4 & Lack of understanding of PC & 0.230 & 0.002 & 0.001 & I & 0.020 & 0.328 & 0.011 & 0.443 & 0.02 & 0.008 & 0.033 \\
\hline 5 & Inadequate training in $\mathrm{PC}$ & 0.450 & 0.463 & 0.279 & 0.020 & I & 0.001 & 0.388 & 0.410 & 0.051 & 0.452 & 0.389 \\
\hline 6 & $\begin{array}{l}\text { Lack of workplace for counseling } \\
\text { in the pharmacy }\end{array}$ & 0.288 & 0.206 & $0.4 I 5$ & 0.328 & 0.001 & I & 0.454 & 0.085 & 0.303 & 0.363 & 0.160 \\
\hline 7 & $\begin{array}{l}\text { Inadequate technology in the } \\
\text { pharmacy }\end{array}$ & 0.031 & 0.000 & 0.000 & 0.011 & 0.388 & 0.454 & I & 0.025 & 0.432 & 0.084 & 0.051 \\
\hline 8 & Lack of self confidence & 0.169 & 0.324 & 0.013 & 0.443 & 0.410 & 0.085 & 0.025 & 1 & 0.355 & 0.443 & 0.208 \\
\hline 9 & Time constraints (lack of time) & 0.426 & 0.248 & 0.422 & 0.002 & 0.051 & 0.303 & 0.432 & 0.355 & 1 & 0.075 & 0.183 \\
\hline 10 & $\begin{array}{l}\text { Poor image of pharmacist's role } \\
\text { in wards }\end{array}$ & 0.347 & 0.001 & 0.000 & 0.008 & 0.452 & 0.363 & 0.084 & 0.443 & 0.075 & 1 & 0.000 \\
\hline II & Inability to deal with a different sex & 0.268 & 0.180 & 0.004 & 0.033 & 0.389 & 0.160 & 0.051 & 0.208 & 0.183 & 0.000 & 1 \\
\hline
\end{tabular}

Note: The significant values are in bold type.

Abbreviation: PC, pharmaceutical care. 
training during their clerkship at experiential training sites, the students might be more likely to assume an active role in offering PC during their professional practice. Recognition of the value of pharmacy is paramount in preventing and managing drug therapy problems. Students in our study showed good skills in identifying and managing drug therapy problems. The clerkship experience will be helpful to them in terms of applying their theoretical skills in providing patient-centered care. These findings are consistent with a study conducted by Rovers et $\mathrm{al}^{22}$ that showed that experiential training helped clerkship students identify drug therapy problems upon using a guided interview process to interview patients.

Although this study showed a high degree of positive attitude among the final year students toward the implementation of PC, it is important for these same students, upon graduation, to want to implement PC service in hospitals and other practice sites. This may help to boost their professional image in their workplace and improve the care delivery process in hospitals. Engaging clinical pharmacists in the entire patient care process, from initial assessment through documentation to follow-up evaluation in various patient wards, can create a significant difference in improving patient care. Clinical pharmacists can aid in designing and developing PC through individual patient care plans and treatment interventions. Future researches may include interventional studies that could evaluate the extent of team collaboration and communication support to PC.

\section{Limitations}

We used a standardized PCAS questionnaire using the cross-sectional study method to assess the attitude of the first-batch clinical clerkship students to reduce selection bias. Open-ended questions were limited in the questionnaire and the study was pilot tested. Further, the attitude and barriers were tested using different questions to reduce information bias.

However, the study is not without limitations. It was conducted in a single institution and the results might not be generalizable to other pharmacy schools in Ethiopia. In addition, data presented here is self-report, and some of the respondents may provide extreme responses as compared to others, due to the motivations and beliefs of the respondents, and might be subject to recall bias.

\section{Conclusion}

Ethiopian clinical pharmacy students have a good attitude toward PC. Unnecessary drug therapy, drug interactions, and medication non-adherence were some of the drug therapy issues that pharmacists encountered while providing PC. Efforts should be targeted toward reducing these drug therapy issues and aiding the integration of $\mathrm{PC}$ provision with pharmacy practice.

\section{Acknowledgment}

The authors wish to thank all the pharmacy student participants for their contribution and further thank all the faculty members of the School of Pharmacy, University of Gondar-College of Medicine and Health Sciences, Gondar, Ethiopia. Their special thanks go to Isha Patel and Tahir Mehmood Khan for support in fulfilling this research work.

\section{Disclosure}

The authors declare no conflicts of interest in this work.

\section{References}

1. American College of Clinical Pharmacy. The definition of clinical pharmacy. Pharmacotherapy. 2008;28:816-817.

2. Helper CD, Strand LM. Opportunities and responsibilities in pharmaceutical care. Am J Hosp Pharm. 1990;47:533-543.

3. Bond CA, Raehl CL, Franke T. Clinical pharmacy services and hospital mortality rates. Pharmacotherapy. 1999;19:556-564.

4. Westerlund T, Marklund B. Assessment of the clinical and economic outcomes of pharmacy interventions in drug-related problems. J Clin Pharm Ther. 2009;34:319-327.

5. Van Mil JWF, Schulz M. A review of pharmaceutical care in community pharmacy in Europe. Harvard Health Policy Rev. 2006;7(1): $155-168$.

6. Bhagavathula AS, Sarkar BR, Patel I. Clinical pharmacy practice in developing countries: focus on India and Pakistan. Arch Pharma Pract. 2014;5:91-94.

7. Odegard PS, Tadeg H, Downing D, et al. Strengthening pharmaceutical care education in Ethiopia through instructional collaboration. Am J Pharm Educ. 2011;75:134.

8. Mekonnen AB, Yesuf EA, Odegard PS, Wega SS. Implementing ward based clinical pharmacy services in an Ethiopian University Hospital. Pharm Pract (Granada). 2013;11:51-57.

9. Mekonnen AB, Yesuf EA, Odegard PS, Wega SS. Pharmacist' Journey to Clinical Pharmacy Practice in Ethiopia: Key Informants'Perspective. Thousand Oaks: Sage Open Medicine; 2013.

10. Chisholm MA, Wade WE. Factors influencing students' attitudes toward pharmaceutical care. Am J Health Syst Pharm. 1999;56(22): 2330-2335.

11. Al-Arifi MN. Pharmacy students' attitudes toward pharmaceutical care in Riyadh region Saudi Arabia. Pharm World Sci. 2009;31(6): 677-681.

12. Rahim N, Nesar S. Pharmacy undergraduate students' attitude towards providing Pharmaceutical Care in Pakistan. Int J Pharm Pharm Sci. 2012;4(4):113-116.

13. Martin BC, Chisholm MA. Cross-validation of an instrument measuring students attitudes toward pharmaceutical care. Am J Pharm Educ. 1999;63:46-51.

14. El Hajj MS, Hammad AS, Afifi HM. Pharmacy students' attitude towards pharmaceutical care in Qatar. Ther Clin Risk Manag. 2014;10: 121-129.

15. Udeogaranya PO, Ukwe CV, Ekwunife OI. Assessment of attitudes of University of Nigeria pharmacy students toward pharmaceutical care. Pharm Pract. 2009; 7(3):145-149. 
16. Ubaka CM, Ekwunife OI, Adibe MO. Does the clinical clerkship course improve students' attitude towards pharmaceutical care? Int J Pharm Prac. 2012;00:1-3.

17. El Hajj MS, Salem S, Mansoor H. Public's attitudes towards community pharmacy in Qatar: a pilot study. Patient Prefer Adherence. 2011;5: 405-422.

18. Chisholm MA, Martin BC. Development of an instrument to measure student attitudes concerning pharmaceutical care. Am J Pharm Educ. 1997;61:374-379.

19. Morello CM, Zadvorny EB, Cording MA, Suemoto RT, Skog J, Harari A. Development and clinical outcomes of pharmacist-managed diabetes care clinics. Am J Health Syst Pharm. 2006;63(14):1325-1331.
20. Farris KB, Fernandez-Llimos F, Benrimoj SI. Pharmaceutical care in community pharmacies: practice and research from around the world. Ann Pharmacother. 2005;39(9):1539-1541.

21. Fang Y, Yang S, Feng B, Ni Y, Zhang K. Pharmacists' perception of pharmaceutical care in community pharmacy: a questionnaire survey in Northwest China. Health Soc Care Community. 2011;19(2):189-197.

22. Rovers J, Miller MJ, Koenigsfeld C, Haack S, Hegge K, McCleeary E. A guided interview process to improve student pharmacists' identification of drug therapy problems. Am J Pharm Educ. 2011;75(1) Article16.

\section{Publish your work in this journal}

Advances in Medical Education and Practice is an international, peerreviewed, open access journal that aims to present and publish research on Medical Education covering medical, dental, nursing and allied health care professional education. The journal covers undergraduate education, postgraduate training and continuing medical education including emerging trends and innovative models linking education, research, and health care services. The manuscript management system is completely online and includes a very quick and fair peer-review system. Visit http://www.dovepress.com/testimonials.php to read real quotes from published authors.

Submit your manuscript here: http://www.dovepress.com/advances-in-medical-education-and-practice-journal 